\title{
Is medicine still a profession?
}

$\mathrm{T}$ here must be something to this question, given the increasing number of medical associations that are issuing proclamations to promote professionalism. Among these is a report published in the UK late last year by the Royal College of Physicians. ${ }^{1}$ In that document, a panel of experts defines the core values of the medical profession as integrity, compassion, altruism and excellence. No argument there. But these are glued to a set of "values," including teamwork and continuous improvement, that seem to have more to do with modern managerial concepts than with the core components of medical professionalism.

It seems that the venerable model of the wise and trusted physician is being prodded by watchwords like "quality," "timeliness" and "accountability." An increasingly skeptical public is demanding that professional societies set practice standards, measure adherence and publish individual report cards. The credentials of age, experience and reputation are being replaced by continuing education credits and practice audits of increasing specificity.

The social analyst Jane Jacobs perceives two broad types of work ethic in modern societies: the "commercial moral syndrome" and the "guardian moral syndrome." Each, according to Jacobs, works within a system of values. Guardians value tradition, altruism, hierarchy and exclusivity. Medicine, at least as practised up until about 30 years ago, aligns well with the attributes of the latter category: physicians are guardians of a body of knowledge that is largely exclusive to themselves.

But today, the exclusivity of that domain is being breached on two fronts. First, there is a leakage of physicians' authority resulting from the better education and empowerment of patients. Some patients suffering from a single disease may be better informed about their condition than their physicians, who must keep track of hundreds. Second, an erosion of guardianship is resulting from commercialization of the medical knowledge base. Medical science, especially as it applies to practice, is increasingly controlled by private companies whose values, belonging to the "commercial moral syndrome," are competitive, contractual, thrifty and industrious. More and more, those values are shaping how medical knowledge is amassed: from the choice of proposals to evaluate, to the design, analysis and publication of research, commercial interests introduce a bias toward initiatives that will have a positive impact on profits first and on populations second.
Further, to keep up to date with modern medical science, physicians have to rely (and indeed are encouraged to rely) on various summaries of that science in the form of narrative and systematic reviews in peer-reviewed journals, clinical practice guidelines and continuing medical education. But these, too, are being increasingly distorted by commercial self-interest. Thus, not only is the privileged knowledge the profession once possessed no longer exclusive (a good thing), but the integrity of that knowledge is being corroded by commercial interests (not a good thing).

At the same time, excellent health care requires more than a quickly accessed digest of randomized clinical trials. At the bedside of a sick patient it requires judgment, based on training, experience and insight into each patient's particular predicament. The core value of intelligent and well-informed altruism is at the heart of medical professionalism, and it is this value that is slipping on the grease of commercial interests and their distortion of the knowledge base.

The profession and their professional associations can probably do little to patch the leaks resulting from the commercialization of applied medical science, but they can do a lot to stop the flow from distorted and biased continuing education. Physicians and their professional associations would do well to follow the lead proposed by a group of experts in the US and cut the ties between commercial interests and the profession's knowledge base. ${ }^{3}$ They propose that the profession set standards that would eliminate commercial gifts, free samples, participation by faculty on speaking bureaus and on hospital formulary committees when they have a financial conflict of interest, professional participation in various activities of research consulting and research contracts that have no specific deliverables, and that would erect unbreachable walls between industry and continuing medical education in all its forms. In short, to restore the scientific integrity of medicine as a profession, we must regulate and in some cases eliminate the influence of commercial interests whose values require a primary commitment to increasing value for shareholders, not patients. - CMAJ

\section{REFERENCES}

I. Horton R. Medicine: the prosperity of virtue. Lancet 2005;366:1985-7.

2. Jacobs J. Systems of survival: a dialogue on the moral foundations of commerce and politics. New York: Random House; 1992.

3. Brennan TA, Rothman DJ, Blank L, et al. Health industry practices that create conflicts of interest: a policy proposal for academic medical centers. JAMA 2006;295:429-33. 